Neurosurg Focus 28 (4):E10, 2010

\title{
Radiation therapy for pediatric craniopharyngioma
}

\author{
Erin N. Kiehna, M.D., ${ }^{1}$ And Thomas E. Merchant, D.O., Ph.D. ${ }^{2}$ \\ ${ }^{1}$ Department of Neurological Surgery, University of Virginia Health System, Charlottesville, Virginia; \\ and ${ }^{2}$ Division of Radiation Oncology, St. Jude Children's Research Hospital, Memphis, Tennessee
}

\begin{abstract}
Object. The treatment of craniopharyngioma is highly controversial. Continued advances in limited surgery and radiation therapy have maintained excellent local disease control while minimizing treatment-related sequelae. Further analyses of outcomes are necessary to characterize the long-term effects of radiation therapy.

Methods. An extensive literature review was performed for all studies including radiation therapy, with or without surgery, for pediatric craniopharyngioma.

Results. The authors identified 32 papers describing radiation therapy for treatment of pediatric craniopharyngioma, with disease control ranging from 44 to $100 \%$. Modern studies report at least $90 \%$ disease control with 5-year follow-up. Fifteen studies reported outcomes, demonstrating that more than two-thirds of patients treated with surgery and radiation therapy have favorable outcomes, and this rate is more than $85 \%$ in the modern era.

Conclusions. Conservative surgery and radiation therapy results in long-term disease control in pediatric patients with craniopharyngioma that is comparable to results obtained with radical surgery alone. However, children with craniopharyngioma remain vulnerable to late treatment failures and side effects from radiation therapy, including endocrinopathies, vasculopathies, and secondary tumors, which may be detrimental to the quality of life. Long-term follow-up beyond 5-10 years is necessary to assess tumor control relative to functional outcomes. (DOI: 10.3171/2010.1.FOCUS09297)
\end{abstract}

\section{KEY WORDS - conformal radiation therapy - craniopharyngioma}

$I^{2}$ N 1932, Harvey Cushing described craniopharyngioma as "the most baffling problem which confronts the neuro-surgeon." In 2 detailed accounts, he described performing frontal craniotomies for cystic fenestration of these lesions, only to have to return for subsequent fenestration and cystic resection due to symptomatic cystic recurrence. ${ }^{21,40}$ The treatment of craniopharyngioma remains equally challenging and controversial in 2010 . Although craniopharyngioma is pathologically benign in children, and should be curable by complete surgical removal, the morbidity and mortality associated with such attempts may be avoided by using a multimodality approach.

In 1961, Kramer et al. ${ }^{18}$ at the Royal Marsden Hospital became the first group to publish a report on limited surgery and radiation therapy for pediatric craniopharyngioma. They recognized that with fenestration alone, symptomatic regrowth of the cystic portion of the tumor could be expected within 3-6 months. ${ }^{14}$ By combining bur-hole aspiration with external-beam radiation therapy to 5000-6550 R, disease control was achieved in all 6 children who were reported to be "alive and well" at follow-up. Long-term disease control and outcomes in this group of patients were updated by Rajan et al. ${ }^{32}$ in 1993, in an expanded cohort of 77 children also treated with planned limited surgery and radiation. The 10-year

Abbreviation used in this paper: DI = diabetes insipidus. progression-free survival rate was $80 \%$ and overall survival was $77 \%$. These results were comparable to major surgical series at that time.

Over the past decade, advances in image guidance and conformal radiation therapy have allowed for precise tumor localization and smaller treatment margins to limit the radiation dose to normal brain. Our preliminary experience with conformal radiation therapy for children with craniopharyngioma, both newly diagnosed and recurrent after prior surgery, showed that the volume of irradiation could be reduced without affecting the expected rate of tumor control. With a median follow-up period of 36.6 months (range $24.4-80$ months), the 3 -year estimate of progression-free survival was $90.3 \pm 7.3 \% .^{25}$ Longitudinal evaluation of IQ in these patients showed a negative correlation between IQ and the volume of normal brain receiving doses in excess of $45 \mathrm{~Gy}$ as well as a variety of surgical factors, most notably extent of resection. In this preliminary experience in which conformal radiation therapy was used, the clinical target volume margin surrounding the cystic solid tumor complex was relatively large $(10 \mathrm{~mm})$ for a tumor known to lack invasive properties. The clinical target volume margin was subsequently reduced to $5 \mathrm{~mm}$, and with additional follow-up, disease control outcomes parallel those achieved in earlier reports in which conventional radiation therapy was used. Despite these advances in reducing dose to normal tissue, we recognize that these children are vulnerable to 


\section{E. N. Kiehna and T. E. Merchant}

radiation sequelae that may be delayed in presentation. We have evaluated these patients for other measures, including behavior, to show that good functional outcomes may be achieved, and to show the contribution of factors other than radiation therapy to late effects. ${ }^{8}$

In this review we compare results of combined surgery and radiation therapy for pediatric craniopharyngioma, distinguishing outcomes for pediatric patients separately from adults to account for differences in natural history, which may lead to bias in selecting treatment, reporting tumor- and treatment-related complications, and outcome measures including quality of life.

\section{Radiation Therapy for Pediatric Craniopharyngioma}

We searched the literature for all published reports of radiation therapy for craniopharyngioma. Articles were excluded if specific results for children were not listed in the text. Table 1 summarizes the results of our review, based on series grouped by institution, number of patients, age, and follow-up and disease control, as reported in the original articles. Studies using statistical methods to estimate survival have been identified.

The earliest reports of radiation therapy for pediatric craniopharyngioma are from the Royal Marsden Hospital. Between 1952 and 1954 at that institution, 6 children underwent attempted stereotactic aspiration of cyst contents, followed by radiotherapy consisting of 2 arcs of $180^{\circ}$, delivering $5500 \mathrm{R}$ over 6 weeks. Without the advantages of modern imaging, radiation was aimed at either the sella turcica for uncalcified tumors or at calcifications beyond the sella and presumed to be tumor. All 6 children were alive and free from disease recurrence over a follow-up period of 6 years..$^{18}$ During the ensuing decades, 188 patients received conservative surgery followed by external-beam radiation therapy at the Royal Marsden Hospital, 72 of whom were younger than 16 years of age. This represents experiences with one of the largest and most mature patient groups. During this time period, the linear accelerator replaced ${ }^{60} \mathrm{Co}$ radiation, allowing for a more predictable and precise method of delivering radiation therapy. Only 8 of these children experienced disease progression, resulting in an estimated progression-free survival rate of $84 \%$ when measured beyond 10 years. ${ }^{1,33}$

In addition to advances in the delivery of radiation with the linear accelerator, CT scans became readily available in the 1970s, as did the operating microscope. Many centers began retrospectively stratifying children into treatment groups for analysis of outcomes. At the University of California, San Francisco, patients who underwent biopsy sampling or cyst resection and radiation had $100 \%$ disease control, whereas in more than half of the children undergoing subtotal resection and radiation, the treatment failed. ${ }^{19,36,44}$ Similarly, children treated with conservative surgery and radiation in Boston experienced 95-100\% disease control, whereas patients treated with subtotal resection and radiation only achieved $67-83 \%$ disease control. .938 Sung ${ }^{42}$ reported $87 \%$ disease control with minimal surgery and radiation therapy, and $72 \%$ disease control for patients undergoing subtotal surgery at Columbia. Overall, despite advances in neuroimaging and surgical technique, these results suggested that extensive resection does not improve disease control rates when adjuvant radiation therapy is used.

More modern studies conducted between 1980 and 2000 confirmed that conventional radiation therapy resulted in disease control rates ranging from 79 to $84 \%$ at 10 years. ${ }^{28,30,41}$ These series also analyzed many treatment-related factors involving the delivery of radiation therapy. Moon et al..$^{28}$ analyzed the timing of radiation therapy following surgery and found no significant difference between early and late treatment. Radiation therapy was also found to be highly effective as salvage therapy for patients in whom initial surgery failed. . $^{25,30,41}$

Since 1998, in an effort to reduce the side effects, we have prospectively used conformal and intensity-modulated radiation therapy for the treatment of craniopharyngioma instead of conventional radiation therapy, which in the past included large, parallel, opposed beams. Modern radiation therapy treatment planning involves the use of CT imaging to define the frame of reference and calculate radiation dose. Registration of MR imaging data has further refined target delineation, which is based on the gross tumor volume that includes the entire residual solid and cystic tumor. Relative to the start of treatment, the timing of imaging and the acquired sequences ensures delineation of the proper target and reduces error associated with changes in the tumor over time. Imaging during therapy is critical, because these tumors are known to demonstrate cyst enlargement in response to irradiation. The target for treatment planning comprises the gross tumor volume, defined above, which is then surrounded by the clinical target volume margin to account for subclinical tumor infiltration and uncertainty in interpretation. Our current clinical target volume margin is $5 \mathrm{~mm}$, and may be anatomically constrained at interfaces (for example, bone) where invasion is unlikely. Others have reported applying smaller margins with increasing requirements for stereotactic localization. Finally, the clinical target volume margin is surrounded by a geometrical margin called the planning target volume margin. This margin has been reduced to approximately $3 \mathrm{~mm}$ for daily clinical radiotherapy with the advent of linear accelerator on-board imaging systems, which are capable of daily cone-beam CT imaging. As the margins continue to shrink while practitioners gain more experience, it is critical that the images used to define the target have compatible resolution. In our experience, 3D MR imaging using postcontrast T1-weighted, T2-weighted, and postcontrast T2-weighted FLAIR imaging appear to be most useful. The T2-weighted imaging is critical at interfaces involving normal brain, whereas the postcontrast T2-weighted FLAIR imaging is key to defining tumor that interfaces with CSF. Our disease control for patients treated with surgery and radiation therapy is 90 and $85 \%$ at 3 and 5 years, respectively. ${ }^{25}$ Puget et al. ${ }^{31}$ have reported no treatment failures with this approach at a 14-month follow-up.

Patients treated with focused radiation require imaging during treatment to monitor for cyst progression, which may occur early or late during the treatment 
Radiation therapy for pediatric craniopharyngioma

TABLE 1: Literature review of radiation therapy for pediatric craniopharyngioma*

\begin{tabular}{|c|c|c|c|c|}
\hline Authors \& Year & Pts' Median Age in Yrs (range) & No. of Pts & FU (yrs) & $\%$ Disease Control \\
\hline Kramer et al., 1961 & $10(6-14)$ & 6 & 6 & 100 \\
\hline Bloom et al., 1990 & & 27 & 10 & 96 \\
\hline Rajan \& coll, 1993, 1997 & $<16$ & 72 & 10 & $87 \dagger$ \\
\hline McMurry et al., 1977 & $<18$ & 6 & 10 & 77 \\
\hline Lichter et al., 1977 & $10(4-17)$ & 7 & 6 & 71 \\
\hline Thomsett et al., 1980 & $9.2(1.8-17.2)$ & 7 & 4.5 & 82 \\
\hline Richmond et al., 1980 & $<20$ & & & \\
\hline$S T R+R T$ & & 12 & 5 & 44 \\
\hline$b x+R T$ & & 8 & 5 & 100 \\
\hline Onoyama et al., 1977 & $<25$ & 12 & 10 & 77 \\
\hline Thompson et al., 1978 & $10(5-18)$ & 5 & 3.5 & 60 \\
\hline \multicolumn{5}{|l|}{ Shapiro et al., 1979} \\
\hline$S T R+R T$ & 7.10 & 7 & 9.4 & $50 \dagger$ \\
\hline$b x+R T$ & 7.93 & 22 & 3.3 & $100 \dagger$ \\
\hline Cabezudo et al., 1981 & $<15$ & 9 & 3 & $100 \dagger$ \\
\hline Sung, 1982 & $<15$ & 14 & 10 & \\
\hline$S T R+R T$ & & & & 72 \\
\hline$b x+R T$ & & & & 87 \\
\hline Calvo et al., 1983 & $10(3-19)$ & 11 & 6 & 100 \\
\hline Hoogenhout et al., 1984 & $<15$ & 12 & 10 & $86 \dagger$ \\
\hline Manaka et al., 1985 & $<14$ & 21 & 10 & $63 \dagger$ \\
\hline Clayton et al., 1988 & $9.5(1-16)$ & 10 & 6.3 & 100 \\
\hline Sorva et al., 1988 & $11(1-18)$ & 22 & & \\
\hline$S T R+R T$ & & & 5 & 100 \\
\hline$b x+R T$ & & & 5 & 100 \\
\hline Wen et al., 1989 & $<18$ & 8 & 5 & 100 \\
\hline Shillito, 1986 & & 10 & & \\
\hline$S T R+R T$ & 3.45 (11 mos-15 yrs) & 6 & 10 & 67 \\
\hline$b x+R T$ & $11.4(6-13)$ & 4 & 10 & 100 \\
\hline Fischer et al., 1990 & & 27 & 10 & \\
\hline$S T R+R T$ & 7.4 & 4 & 11 & 83 \\
\hline$b x+R T$ & 9.6 & 16 & 10 & 95 \\
\hline Danoff et al., 1983 & $8(3-19)$ & 19 & & \\
\hline$S T R+R T$ & & & 10 & 50 \\
\hline$b x+R T$ & & & 10 & 83 \\
\hline Weiss et al., 1989 & $10(3-14)$ & 5 & 7 & 80 \\
\hline Regine \& coll, 1992, 1993 & $<16$ & 19 & 10 & 75 \\
\hline Hetelekidis et al., 1993 & & 37 & 4 & 86 \\
\hline Stripp et al., 2004 & $8.5(1.5-24)$ & 18 & 10 & $84 \dagger$ \\
\hline Moon et al., 2005 & $<20$ & 15 & 10 & $80 \dagger$ \\
\hline Pemberton et al., 2005 & $<15$ & 28 & 10 & $79 \dagger$ \\
\hline Habrand et al., 1999 & $7.4(2-15)$ & 37 & 10 & $56 \dagger$ \\
\hline Puget et al., 2007 & & 22 & & 100 \\
\hline STR + RT (retrospective) & $7.5(4-16)$ & 8 & 10 & 100 \\
\hline STR + RT (prospective) & $7.9(2-14)$ & 10 & 1 & 100 \\
\hline Lin et al., 2008 & $9(2-14)$ & 11 & 10 & $100 \dagger$ \\
\hline
\end{tabular}


TABLE 1: Literature review of radiation therapy for pediatric craniopharyngioma* (continued)

\begin{tabular}{|c|c|c|c|c|}
\hline Authors \& Year & Pts' Median Age in Yrs (range) & No. of Pts & FU (yrs) & $\%$ Disease Control \\
\hline Merchant et al., 2002 & $7.3(3-18)$ & 15 & 6 & 94 \\
\hline Merchant et al., 2006 & $7.3(3-18)$ & 28 & 3 & $90 \dagger$ \\
\hline
\end{tabular}

course. ${ }^{33}$ Our current protocol includes weekly MR imaging, rapid assessment of changes in the target volume through imaging registration, and development of a new (adaptive) treatment plan when the gross tumor volume intersects with the clinical target volume at any point. Although there is no consensus in the literature on the treatment dose and fractionation schedule, the majority of series limited radiation dose to 50-55.8 Gy in children, delivered in 1.5- to 2.0-cGy fractions, 5 days per week for a period of 6 weeks. Concerns about the maximum dose to the optic chiasm and optic nerves precludes treatment to higher doses.

\section{Side Effects After Radiation Therapy}

Treatment-related side effects of radiation therapy have been well described in the literature, and include endocrine, visual, and cognitive sequelae as well as vasculopathy and secondary malignancies. Side effects may occur acutely, but are generally considered to be insidious. Regardless of their timing, they have the ability to affect the quality of life of these children. ${ }^{16}$

\section{Visual Outcomes}

Visual deterioration occurring during radiation therapy has been well documented, and is usually attributed to cystic progression and/or hydrocephalus. ${ }^{33}$ Craniotomy and tumor decompression is sometimes required, but more often cyst aspiration alone reverses vision loss when performed in a timely manner. Aspiration may need to be performed repeatedly. The historical incidence is approximately $14 \% .{ }^{33}$ In our series, up to $46 \%$ of patients required cyst aspiration in the time period immediately before, during, or after radiation therapy. ${ }^{25}$ Optic neuropathies and/or necrosis may also occur secondary to radiation therapy, and appear to be dose dependent. ${ }^{11,13,25,30,32,34,35,41,46}$ Flickinger et al. ${ }^{10}$ reported on 3 children in whom optic neuropathy developed at a radiation dose in excess of 60 Gy. We have not experienced any occurrences of optic neuritis or necrosis when the optic apparatus is treated to 54-55.8 Gy in 1.8-Gy fractions, a consensus dose in the literature. ${ }^{27}$ We recently reviewed a cohort of 62 children, and found that $38(61 \%)$ had normal vision, $14(23 \%)$ had mildly to moderately impaired vision, and $10(16 \%)$ had severely impaired vision at the start of irradiation. With extended follow-up, none of the patients had clinically significant changes in their vision that were not attributed to tumor progression. Only $5 \%$ required craniotomy for decompression when cystic change affected vision early after radiation therapy, and placement of an Ommaya reservoir was considered not to be feasible.

\section{Endocrine Outcomes}

Hypothalamic-pituitary dysfunction may result from the tumor burden alone; however, progressive pituitary dysfunction develops in the months to years following radiation therapy and must be closely monitored. ${ }^{11,12,25} \mathrm{With}$ long-term follow-up we have found that up to $70 \%$ of children require growth hormone supplementation, $90 \%$ require thyroid replacement, $40 \%$ require replacement for hypogonadism, and $75 \%$ require cortisol supplementation. The incidence of DI after radiotherapy is strictly related to changes in the tumor complex that mechanically impact the pituitary. In general, DI is not considered a common complication of irradiation. The incidence of the more common endocrine deficiencies appears to be dose dependent. At levels higher than $60 \mathrm{~Gy}$ it may be as high as $80 \%$, versus $36 \%$ incidence at lower doses. ${ }^{34}$

\section{Cognitive Outcomes}

Early attempts to quantify the effects of surgery and adjuvant therapy on cognitive outcomes demonstrated that patients treated with primary radiation for craniopharyngioma had less frontal lobe dysfunction than patients who underwent radical excision. ${ }^{4}$ As radiation treatment has become more conformal, with a reduction in dose to the normal brain, children are tolerating radiation therapy without treatment-related decline..$^{9,25,26,28,30,32,35,41}$ Our results with serial neuropsychometric testing show that overall IQ remains stable through 5 years of follow-up; however, there are factors that predispose some patients to worse outcomes. These characteristics include younger patients (age $<7$ years) and those with hydrocephalus treated with shunt insertion, large cystic tumors requiring multiple aspirations, extensive surgery, and DI. ${ }^{25}$ Jalali et al. ${ }^{15}$ also demonstrated that IQ remains stable over a 2 -year period, and that age $<15$ years was a significant cause of decline, as was dose to the temporal lobe.

\section{Functional Outcomes and Quality of Life}

Fifteen articles published during the past 50 years have reported on functional and neurological outcomes following radiation therapy. The first children treated in a combined-modality approach were reported to have a $6 \%$ disability rate, with a median follow-up of 12 years. ${ }^{32}$ With the use of more standardized scales of quality of life and performance status, including the Wen classification 
index, Wechsler IQ and achievement tests, and Health Utility Index, 42-86\% of patients treated with surgery and conventional radiation therapy have experienced a favorable functional outcome, defined as limited disability and functional independence, with improved scores in the more modern treatment era (Table 2). With a conversion to conformal radiation therapy, at least $85 \%$ of patients have a favorable outcome, as determined by cognitive testing. ${ }^{26}$

\section{Cerebrovascular Disease}

Radiation therapy targeted at the sellar/suprasellar region will unfortunately also include the intracranial carotid arteries and the circle of Willis. Liu et al. ${ }^{22}$ reported on 6 patients in a series of 20 who developed a vasculopathy on neuroimaging after receiving radiation therapy for craniopharyngioma. Retrospective studies of radiation therapy directed at the sellar/suprasellar region have demonstrated an incidence as high as $21 \%$ for cerebrovascular events. ${ }^{17}$ The treatment of vasculopathy and moyamoya disease should be approached systematically and cautiously by experienced caregivers, because the risks associated with treatment have been considerable. The relative risk of developing moyamoya has been estimated to increase by $7 \%$ for every $100 \mathrm{cGy}$ increase in radiation dose above $5000 \mathrm{cGy}$. The delay to occurrence is approximately $5-12$ years. ${ }^{12,45}$

\section{Secondary Malignancies}

The risk of a radiation-induced secondary malignancy is estimated to be $1.9 \%$ at 10 years, and remains a primary concern when managing craniopharyngioma in these children. ${ }^{16}$ In the largest single-institution study of 173 patients who were treated with conservative surgery and radiation therapy, no secondary malignancies were reported at a median follow-up of 12 years. ${ }^{32}$ Of the 626 patients in our literature review, the majority of whom received conventional radiation, there are only 4 reports of secondary malignancies. These were all high-grade glioma, of which the patients subsequently died..$^{9,11,38}$ In the modern treatment era, in which radiation is delivered in a conformal fashion, minimizing the dose to normal tissue, the rate of secondary malignancy may decline. The development of malignant craniopharyngioma after radiation therapy is considered a secondary malignancy by transformation, and it is rare.

\section{Conclusions}

We have reviewed the role of radiation therapy in the treatment of pediatric craniopharyngioma at more than 20 major medical centers worldwide over the course of nearly 50 years. When craniopharyngioma is treated using a multidisciplinary approach involving neurosurgeons, neurooncologists, and radiation oncologists, conservative surgery and radiation therapy results in longterm disease control in pediatric craniopharyngioma, and the control is comparable to results obtained with radical surgery alone. However, our results at present are limited to studies with only 5- to 10 -year reported
TABLE 2: Literature review of neurological outcomes after radiation therapy for pediatric craniopharyngioma

\begin{tabular}{lc}
\hline \multicolumn{1}{c}{ Authors \& Year } & \% Favorable Functional Outcomes \\
\hline Kramer et al., 1961 & 83 \\
Rajan \& coll, 1993, 1997 & 94 \\
Lichter et al., 1977 & 57 \\
Thomsett et al., 1980 & 89 \\
Sung, 1982 & 54 \\
Shillito, 1986 & \\
STR + RT & 50 \\
bx + RT & 75 \\
Fischer et al., 1990 & \\
STR + RT & 67 \\
bx + RT & 86 \\
Danoff et al., 1983 & 79 \\
Weiss et al., 1989 & 80 \\
Regine \& coll, 1992, 1993 & 42 \\
Pemberton et al., 2005 & 75 \\
Habrand et al., 1999 & 66 \\
Puget et al., 2007 & \\
STR + RT (retrospective) & $76-80$ \\
STR + RT (prospective) & 95 \\
Lin et al., 2008 & 91 \\
Merchant et al., 2002 & 85 \\
\hline
\end{tabular}

outcomes. At present children with this disease have an average life span of 75 years. Children with craniopharyngioma remain vulnerable to late treatment failures and side effects from radiation therapy including endocrinopathy and vasculopathy, which may have a detrimental impact on quality of life. Long-term follow-up beyond 5-10 years is necessary to assess tumor control relative to functional outcomes.

\section{Disclosure}

The authors report no conflict of interest concerning the materials or methods used in this study or the findings specified in this paper.

Author contributions to the study and manuscript preparation include the following. Conception and design: TE Merchant. Acquisition of data: TE Merchant, EN Kiehna. Analysis and interpretation of data: TE Merchant, EN Kiehna. Drafting the article: TE Merchant, EN Kiehna. Critically revising the article: TE Merchant, EN Kiehna. Reviewed final version of the manuscript and approved it for submission: TE Merchant, EN Kiehna. Statistical analysis: TE Merchant, EN Kiehna. Administrative/ technical/material support: TE Merchant. Study supervision: TE Merchant.

\section{References}

1. Bloom HJ, Glees J, Bell J, Ashley SE, Gorman C: The treatment and long-term prognosis of children with intracranial tumors: a study of 610 cases, 1950-1981. Int J Radiat Oncol Biol Phys 18:723-745, 1990

2. Cabezudo JM, Vaquero J, Areitio E, Martinez R, de Sola RG, Bravo G: Craniopharyngiomas: a critical approach to treatment. J Neurosurg 55:371-375, 1981 
3. Calvo FA, Hornedo J, Arellano A, Sachetti A, de la Torre A, Aragon G, et al: Radiation therapy in craniopharyngiomas. Int J Radiat Oncol Biol Phys 9:493-496, 1983

4. Cavazzuti V, Fischer EG, Welch K, Belli JA, Winston KR: Neurological and psychophysiological sequelae following different treatments of craniopharyngioma in children. J Neurosurg 59:409-417, 1983

5. Clayton PE, Price DA, Shalet SM, Gattemaneni HR: Craniopharyngioma recurrence and growth hormone therapy. Lancet 1:642, 1988

6. Cushing H: Intracranial Tumours. Notes Upon a Series of Two Thousand Verified Cases With Surgical-Mortality Percentages Pertaining Thereto. Springfield, IL: Charles C Thomas, 1932, pp 93, 102

7. Danoff BF, Cowchock FS, Kramer S: Childhood craniopharyngioma: survival, local control, endocrine and neurologic function following radiotherapy. Int J Radiat Oncol Biol Phys 9:171-175, 1983

8. Dolson EP, Conklin HM, Li C, Xiong X, Merchant TE: Predicting behavioral problems in craniopharyngioma survivors after conformal radiation therapy. Pediatr Blood Cancer 52:860-864, 2009

9. Fischer EG, Welch K, Shillito J Jr, Winston KR, Tarbell NJ: Craniopharyngiomas in children. Long-term effects of conservative surgical procedures combined with radiation therapy. J Neurosurg 73:534-540, 1990

10. Flickinger JC, Lunsford LD, Singer J, Cano ER, Deutsch M: Megavoltage external beam irradiation of craniopharyngiomas: analysis of tumor control and morbidity. Int J Radiat Oncol Biol Phys 19:117-122, 1990

11. Habrand JL, Ganry O, Couanet D, Rouxel V, Levy-Piedbois $\mathrm{C}$, Pierre-Kahn A, et al: The role of radiation therapy in the management of craniopharyngioma: a 25-year experience and review of the literature. Int J Radiat Oncol Biol Phys 44: 255-263, 1999

12. Hetelekidis S, Barnes PD, Tao ML, Fischer EG, Schneider L, Scott RM, et al: 20-year experience in childhood craniopharyngioma. Int J Radiat Oncol Biol Phys 27:189-195, 1993

13. Hoogenhout J, Otten BJ, Kazem I, Stoelinga GB, Walder AH: Surgery and radiation therapy in the management of craniopharyngiomas. Int J Radiat Oncol Biol Phys 10:2293-2297, 1984

14. Ingraham FD, Scott HW Jr: Craniopharyngiomas in children. J Pediatr 29:95-116, 1946

15. Jalali R, Mallick I, Dutta D, Goswami S, Gupta T, Munshi A, et al: Factors influencing neurocognitive outcomes in young patients with benign and low-grade brain tumors treated with stereotactic conformal radiotherapy. Int J Radiat Oncol Biol Phys 26 [epub ahead of print], 2009

16. Kalapurakal JA: Radiation therapy in the management of pediatric craniopharyngiomas - a review. Childs Nerv Syst 21:808-816, 2005

17. Keene DL, Johnston DL, Grimard L, Michaud J, Vassilyadi M, Ventureyra E: Vascular complications of cranial radiation. Childs Nerv Syst 22:547-555, 2006

18. Kramer S, McKissock W, Concannon JP: Craniopharyngiomas. Treatment by combined surgery and radiation therapy. $\mathbf{J}$ Neurosurg 18:217-226, 1961

19. Lichter AS, Wara WM, Sheline GE, Townsend JJ, Wilson CB: The treatment of craniopharyngiomas. Int J Radiat Oncol Biol Phys 2:675-683, 1977

20. Lin LL, El Naqa I, Leonard JR, Park TS, Hollander AS, Michalski JM, et al: Long-term outcome in children treated for craniopharyngioma with and without radiotherapy. J Neurosurg Ped 1:126-130, 2008

21. Lindholm J, Nielsen EH: Craniopharyngioma: historical notes. Pituitary 12:352-359, 2009

22. Liu AK, Bagrosky B, Fenton LZ, Gaspar LE, Handler MH, McNatt SA, et al: Vascular abnormalities in pediatric cranio- pharyngioma patients treated with radiation therapy. Pediatr Blood Cancer 52:227-230, 2009

23. Manaka S, Teramoto A, Takakura K: The efficacy of radiotherapy for craniopharyngioma. J Neurosurg 62:648-656, 1985

24. McMurry FG, Hardy RW Jr, Dohn DF, Sadar E, Gardner WJ: Long term results in the management of craniopharyngiomas. Neurosurgery 1:238-241, 1977

25. Merchant TE, Kiehna EN, Kun LE, Mulhern RK, Li CH, Xiong X, et al: Phase II trial of conformal radiation therapy for pediatric patients with craniopharyngioma and correlation of surgical factors and radiation dosimetry with change in cognitive function. J Neurosurg 104 (2 Suppl):94-102, 2006

26. Merchant TE, Kiehna EN, Sanford RA, Mulhern RK, Thompson SJ, Wilson MW, et al: Craniopharyngioma: the St. Jude Children's Research Hospital experience 1984-2001. Int J Radiat Oncol Biol Phys 53:533-542, 2002

27. Minniti G, Esposito V, Amichetti M, Enrici RM: The role of fractionated radiotherapy and radiosurgery in the management of patients with craniopharyngioma. Neurosurg Rev 32:125-132, 2009

28. Moon SH, Kim IH, Park SW, Kim I, Hong S, Park CI, et al: Early adjuvant radiotherapy toward long-term survival and better quality of life for craniopharyngiomas - a study in single institute. Childs Nerv Syst 21:799-807, 2005

29. Onoyama Y, Ono K, Yabumoto E, Takeuchi J: Radiation therapy of craniopharyngioma. Radiology 125:799-803, 1977

30. Pemberton LS, Dougal M, Magee B, Gattamaneni HR: Experience of external beam radiotherapy given adjuvantly or at relapse following surgery for craniopharyngioma. Radiother Oncol 77:99-104, 1005, 2005

31. Puget S, Garnett M, Wray A, Grill J, Habrand JL, Bodaert N, et al: Pediatric craniopharyngiomas: classification and treatment according to the degree of hypothalamic involvement. J Neurosurg 106 (1 Suppl):3-12, 2007

32. Rajan B, Ashley S, Gorman C, Jose CC, Horwich A, Bloom HJ, et al: Craniopharyngioma-a long-term results following limited surgery and radiotherapy. Radiother Oncol 26:1-10, 1993

33. Rajan B, Ashley S, Thomas DG, Marsh H, Britton J, Brada M: Craniopharyngioma: improving outcome by early recognition and treatment of acute complications. Int J Radiat Oncol Biol Phys 37:517-521, 1997

34. Regine WF, Kramer S: Pediatric craniopharyngiomas: long term results of combined treatment with surgery and radiation. Int J Radiat Oncol Biol Phys 24:611-617, 1992

35. Regine WF, Mohiuddin M, Kramer S: Long-term results of pediatric and adult craniopharyngiomas treated with combined surgery and radiation. Radiother Oncol 27:13-21, 1993

36. Richmond IL, Wara WM, Wilson CB: Role of radiation therapy in the management of craniopharyngiomas in children. Neurosurgery 6:513-517, 1980

37. Shapiro K, Till K, Grant DN: Craniopharyngiomas in childhood. A rational approach to treatment. J Neurosurg 50:617623,1979

38. Shillito J Jr: Treatment of craniopharyngioma. Clin Neurosurg 33:533-546, 1986

39. Sorva R, Heiskanen O, Perheentupa J: Craniopharyngioma surgery in children: endocrine and visual outcome. Childs Nerv Syst 4:97-99, 1988

40. Spencer DD: Cohen-Gadol: The Legacy of Harvey Cushing: Profiles of Patient Care. New York: Thieme, 2007, pp $34-43,60-65$

41. Stripp DC, Maity A, Janss AJ, Belasco JB, Tochner ZA, Goldwein JW, et al: Surgery with or without radiation therapy in the management of craniopharyngiomas in children and young adults. Int J Radiat Oncol Biol Phys 58:714-720, 2004

42. Sung DI: Suprasellar tumors in children: a review of clini- 


\section{Radiation therapy for pediatric craniopharyngioma}

cal manifestations and managements. Cancer 50:1420-1425, 1982

43. Thompson IL, Griffin TW, Parker RG, Blasko JC: Craniopharyngioma: the role of radiation therapy. Int J Radiat Oncol Biol Phys 4:1059-1063, 1978

44. Thomsett MJ, Conte FA, Kaplan SL, Grumbach MM: Endocrine and neurologic outcome in childhood craniopharyngioma: Review of effect of treatment in 42 patients. J Pediatr 97:728-735, 1980

45. Ullrich NJ, Robertson R, Kinnamon DD, Scott RM, Kieran MW, Turner CD, et al: Moyamoya following cranial irradiation for primary brain tumors in children. Neurology 68:932938, 2007

46. Weiss M, Sutton L, Marcial V, Fowble B, Packer R, Zimmerman $R$, et al: The role of radiation therapy in the management of childhood craniopharyngioma. Int J Radiat Oncol Biol Phys 17:1313-1321, 1989
47. Wen BC, Hussey DH, Staples J, Hitchon PW, Jani SK, Vigliotti AP, et al: A comparison of the roles of surgery and radiation therapy in the management of craniopharyngiomas. Int J Radiat Oncol Biol Phys 16:17-24, 1989

Manuscript submitted December 15, 2009.

Accepted January 18, 2010.

Portions of this work were presented as proceedings at the International Society of Pediatric Neurosurgery meeting, Capetown, South Africa, in October of 2008, and at the Congress of Neurological Surgeons, New Orleans, Louisiana, in October of 2009.

Address correspondence to: Thomas E. Merchant, D.O., Ph.D., Division of Radiation Oncology, Mail Stop 220, St. Jude Children's Research Hospital, 332 North Lauderdale, Memphis, Tennessee 38105-2794.email: thomas.merchant@stjude.org. 